\title{
Resistless fabrication of embedded nanochannels by FIB patterning, wet etching and atomic layer deposition
}

\section{Han, Zhongmei}

\section{IEEE}

2015

Han , Z , Vehkamäki , M J , Leskelä , M \& Ritala , M K 2015, Resistless fabrication of embedded nanochannels by FIB patterning, wet etching and atomic layer deposition . in Proceedings of the 15th IEEE International Conference on Nanotechnology . IEEE, pp. 1008-1011, International Conference on Nanotechnology , Rome , Italy , 27/07/2015 . < http://ieeexplore.ieee.org/xpl/articleDetails.jsp?arnumber=7388790 >

http://hdl.handle.net/10138/164441

publishedVersion

Downloaded from Helda, University of Helsinki institutional repository.

This is an electronic reprint of the original article.

This reprint may differ from the original in pagination and typographic detail.

Please cite the original version. 


\title{
Resistless Fabrication of Embedded Nanochannels by FIB Patterning, Wet Etching and Atomic Layer Deposition
}

\author{
Zhongmei Han, Marko Vehkamäki, Markku Leskelä and Mikko Ritala \\ Laboratory of Inorganic Chemistry, Department of Chemistry \\ University of Helsinki \\ Helsinki, Finland \\ E-mail: zhongmei.han@helsinki.fi
}

\begin{abstract}
Self-supported $\mathrm{SiO}_{2}$ structures were fabricated from thermal $\mathrm{SiO}_{2} / \mathrm{Si}$ substrates by combining FIB direct writing and selective and anisotropic chemical wet etching of silicon. These structures, such as $\mathrm{SiO}_{2}$ overhangs on the edges of $\mathrm{Si}$ trenches, were then used as templates for $A L D$ of $\mathrm{Ta}_{2} \mathrm{O}_{5}$ to form sealed nanochannels and cavities. The size of trenches formed by etching through openings in the $\mathrm{SiO}_{2}$ increases with $\mathrm{FIB}$ patterning ion dose as well as $\mathrm{KOH}$ etching time. Channel formation results from sealing the trenches by the conformal ALD of $\mathrm{Ta}_{2} \mathrm{O}_{5}$. The $\mathrm{KOH}$ etching time determines the channel size while the ion dose determines final wall thickness after ALD. The fabricated hollow nanochannels are embedded under $\mathrm{SiO}_{2}$ and surrounded by $\mathrm{Ta}_{2} \mathrm{O}_{5}$ on crystalline $\mathrm{Si}$. The channel size reaches $50 \mathrm{~nm}$ by this fabrication approach with a $60 \mathrm{~min} \mathrm{KOH}$ etching time.
\end{abstract}

Keywords - nanochannels; focused ion beam; anisotropic etching; atomic layer deposition; $\mathrm{SiO}_{2} / \mathrm{Si}$

\section{INTRODUCTION}

Nanoscale channels are interesting nanostructures due to their promising applications such as filters, transistors, nanofluidics, and molecule sensors [1-4]. However, precise control of channel size and wall thickness is an issue for many nanochannel fabrication methods. Atomic layer deposition (ALD) is increasingly used in making 3D nanostructures due to the superior conformality and precise film thickness control $[5$, 6]. Ultra-thin films have been deposited by ALD on nanostructured templates such as nanopores [7-9], nanofibers $[8,10-12]$ and nanotubes $[13,14]$ for making 3D nanostructures. Furthermore, the deposited film materials can be selected depending on the application as many materials, including metals, oxides and nitrides, are available as ALD processes [6].

$\mathrm{SiO}_{2}$ is an excellent insulating material and has been widely used in silicon-based devices for electrical and optical applications. Patterning of $\mathrm{SiO}_{2}$ for various applications has been previously reported such as lift-off $[15,16]$, photolithography [17], electron beam lithography [18-20], reactive ion etching [21, 22], dynamical ploughing [23] and focused ion beam (FIB) direct writing [24, 25]. FIB direct writing is a maskless patterning technology for nanostructure fabrication [26]. In FIB systems, gallium is the mostly used liquid metal ion source owning to its low melting point, commercial availability, and long lifetime. The main concern for FIB patterning is the $\mathrm{Ga}^{+}$implantation and damage to the target surface. However, majority of the gallium residue caused by FIB patterning of silicon can be removed by subsequent wet etching in a $\mathrm{KOH} / \mathrm{H}_{2} \mathrm{O}_{2}$ solution at room temperature [27]. $\mathrm{SiO}_{2}$ thin films can be grown easily on silicon wafers by thermal oxidation at high temperatures [28]. The thermal oxidation of silicon forms a stable and near-perfect $\mathrm{SiO}_{2} / \mathrm{Si}$ interface [29]. In addition, the high etching selectivity between $\mathrm{SiO}_{2}$ and $\mathrm{Si}$ in various etchants such as $\mathrm{KOH}$ and $\mathrm{HF}$ solutions makes wet etching also a patterning option for $\mathrm{SiO}_{2} / \mathrm{Si}$ systems.

In this study, we combined FIB direct writing and chemical wet etching of silicon for nanofabrication of $\mathrm{SiO}_{2}$ selfsupported structures from thermal $\mathrm{SiO}_{2}$ on $\mathrm{Si}$ substrates. The fabricated $\mathrm{SiO}_{2} / \mathrm{Si}$ line trenches were used as a template for subsequent ALD of $\mathrm{Ta}_{2} \mathrm{O}_{5}$ to form embedded hollow nanochannels contacting with crystalline silicon. The resulting channels have a controllable width and height down to sub-100 $\mathrm{nm}$. The fabrication process is illustrated in Fig. 1.

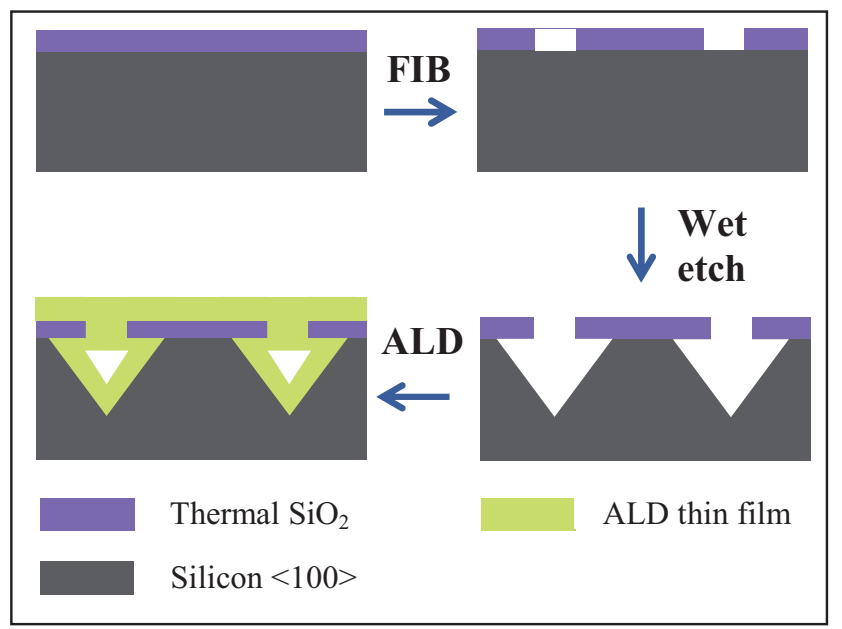

Fig. 1. Schematic illustration of fabrication steps (FIB patterning to open a line on the top $\mathrm{SiO}_{2}$, wet etching of $\mathrm{Si}$ under the $\mathrm{SiO}_{2}$ layer, and ALD of conformal thin film) to form an embedded channel where the channel size, wall material and thickness are controllable. 


\section{EXPERIMENTAL}

\section{A. Fabrication of $\mathrm{SiO}_{2}$ Structures}

Silicon $\langle 100\rangle$ wafers were thermally oxidized $\left(1000{ }^{\circ} \mathrm{C}\right)$ to grow $105 \mathrm{~nm}$ thick $\mathrm{SiO}_{2}$ films. The oxidized wafers were cleaved into small pieces $(2 \mathrm{~cm} \times 5 \mathrm{~cm})$ which were then put into a FIB-SEM chamber for the direct writing by $30 \mathrm{keV}$ gallium ion beam with $100 \mathrm{pA}$ current and $90 \%$ overlap. All the milled structures were aligned with the crystal structure by aligning the milled patterns parallel with the cleaved specimen edge. FIB patterned pieces were wet etched in three successive etching steps. $1 \mathrm{~mol} / \mathrm{L}: 1 \mathrm{~mol} / \mathrm{L} \mathrm{KOH} / \mathrm{H}_{2} \mathrm{O}_{2}$ solution was used immediately at room temperature for 3 hours to remove most of the gallium implanted layer and improve the thermal stability of the FIB patterned sites [27]. $1 \% \mathrm{HF}$ was used to remove native oxide and $1 \mathrm{~mol} / \mathrm{L} \mathrm{KOH}$ to etch the underlying silicon through the opened sites in $\mathrm{SiO}_{2}$ and to release $\mathrm{SiO}_{2}$ with the FIB patterned features.

\section{B. ALD of $\mathrm{Ta}_{2} \mathrm{O}_{5}$ on $\mathrm{SiO}_{2} /$ Si Structures}

ALD of $\mathrm{Ta}_{2} \mathrm{O}_{5}$ was subsequently performed on the FIB patterned and wet etched samples in a Microchemistry F-120 reactor at $250{ }^{\circ} \mathrm{C}$ with $\mathrm{Ta}(\mathrm{OEt})_{5}$ and water as precursors. Long purges were applied during the ALD process in order to remove the precursor vapors as well as possible from the almost-sealed channels.

\section{RESULTS AND DISCUSSION}

\section{A. $\mathrm{SiO}_{2}$ Structures Fabricated by FIB Patterning and Wet Etching}

$\mathrm{Si}$ was etched from the FIB opened sites with $\mathrm{KOH}$ for 2 hours and suspended $\mathrm{SiO}_{2}$ structures were formed due to the etching of Si below (Fig. 2). It is worth emphasizing that the removal of gallium residues with $\mathrm{KOH} / \mathrm{H}_{2} \mathrm{O}_{2}$ is critical for the use of the FIB patterned $\mathrm{SiO}_{2}$ layer as a mask for the $\mathrm{KOH}$ wet etching of the underlying silicon - without the gallium removal the implanted gallium in silicon would stop or delay the following $\mathrm{KOH}$ etching process [27]. This method, combining FIB and wet etching, presents many options for preparing selfsupported or hollow $\mathrm{SiO}_{2}$ structures.

The FIB patterned structures were a circle $(\mathrm{d}=10 \mu \mathrm{m})$, a ring $\left(d_{\text {outer }}=20 \mu \mathrm{m}, d_{\text {inner }}=19.8 \mu \mathrm{m}\right)$, a square matrix $(\mathrm{a}=500$ $\mathrm{nm})$ and a line set on $\mathrm{SiO}_{2} / \mathrm{Si}$ piece before the chemical etching steps. The formed structures under $\mathrm{SiO}_{2}$ shown in Fig. 2(a), (c) and (d) illustrate anisotropic etching of Si (100) and (111) planes while the Fig. 2(b) shows larger underetching resulting from much higher etching rate of (221) and (331) planes than (100) plane [30]. In Fig. 2(b), there is a large space under $\mathrm{SiO}_{2}$ with a supporting pillar in the middle after the $\mathrm{KOH}$ etching of $\mathrm{Si}$. The big membrane plate did not bend towards the bottom of etched $\mathrm{Si}$ in this case probably due to good stiffness of $\mathrm{SiO}_{2}$ film and the anisotropic etching in diluted $\mathrm{KOH}(1 \mathrm{~mol} / \mathrm{L})$ at room temperature. After ALD of $\mathrm{Ta}_{2} \mathrm{O}_{5}$ on the etched $\mathrm{SiO}_{2} / \mathrm{Si}$, the $\mathrm{SiO}_{2}$ plate was FIB cut to the middle to illustrate the cross section (Fig. 3) of the supporting pillar under the suspended $\mathrm{SiO}_{2}$ plate in Fig. 2(b).
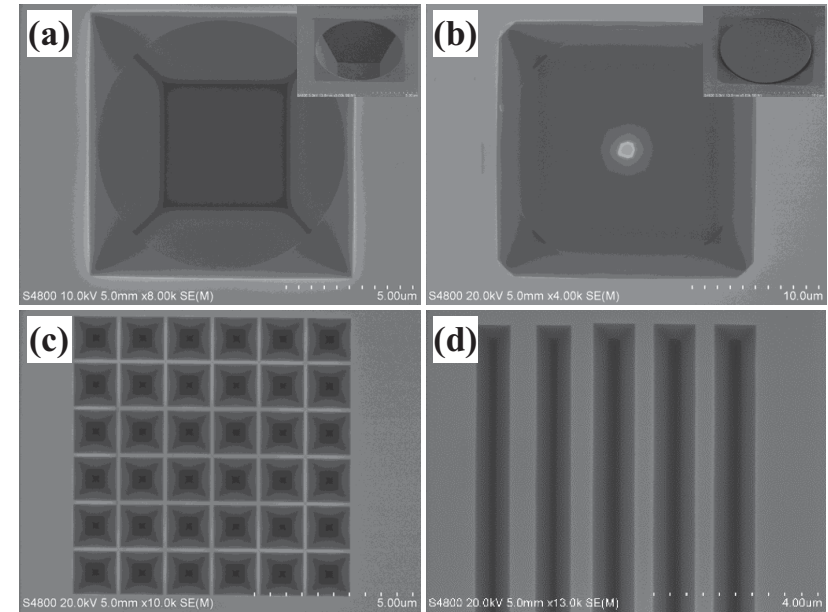

Fig. 2. SEM images of suspended $\mathrm{SiO}_{2}$ structures made by etching with $\mathrm{KOH}$ for $2 \mathrm{~h}$ through different FIB patterned structures in the $\mathrm{SiO}_{2}$ layer: (a) $10 \mu \mathrm{m}$-diameter circle, (b) $200 \mathrm{~nm}$-wide ring (c) square matrix and (d) lines. Inset in (a) and (b) are corresponding tilted images with low voltage (3keV).

Templates for both nanochannels and microcavities can be prepared with this patterning approach, and interconnected networks of reservoirs and channels can be easily prepared with good control of both the size of the features and their relative placement. The ALD-covered membrane surfaces can be easily opened with FIB milling to produce gas or liquid
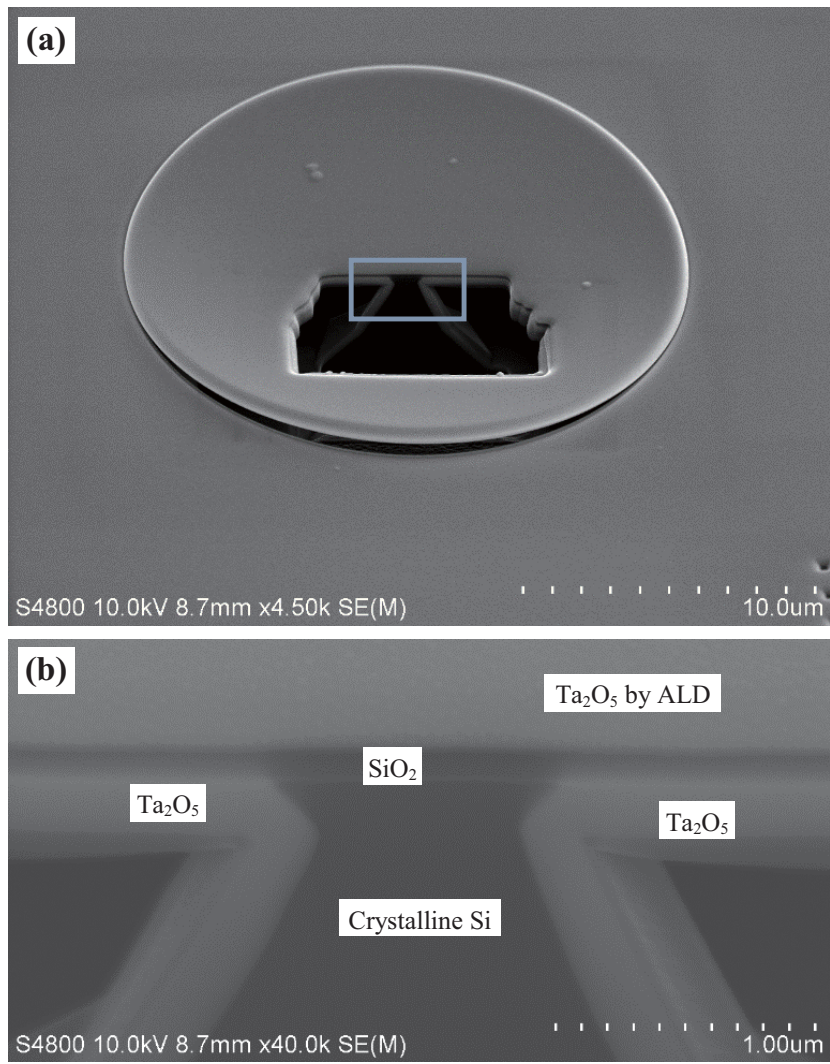

Fig. 3. (a) Cross sectional SEM image of plate-supporting pillar under the $\mathrm{SiO}_{2}$ membrane shown in Fig. 2(b) after ALD of $\mathrm{Ta}_{2} \mathrm{O}_{5}$, and (b) magnified image of the regtangular area in (a). 

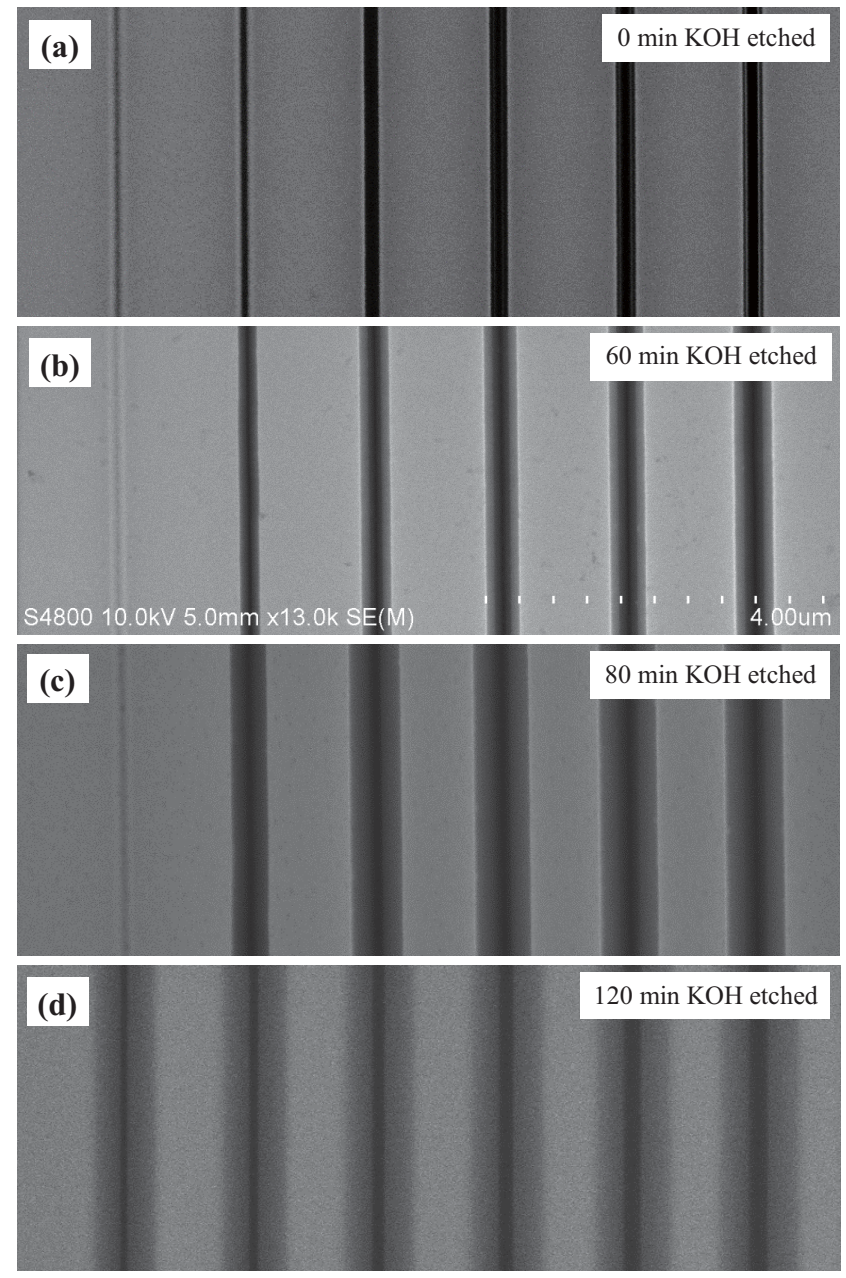

Fig. 4. SEM images of FIB patterned and wet etched line sets which were etched in $\mathrm{KOH}$ for (a) $0 \mathrm{~min}$, (b) $60 \mathrm{~min}$, (c) $80 \mathrm{~min}$ and (d) $120 \mathrm{~min}$. The line separations were all set to $1.5 \mu \mathrm{m}$.

\section{inlets of desired size, for example.}

For line trenches, the patterning ion dose and $\mathrm{KOH}$ etching time are significant for the resulting trench size. Fig. 4 shows top-views of four line sets patterned by FIB with various ion doses followed by wet etching in the $\mathrm{KOH}$ etchant for $0,60,80$ and $120 \mathrm{~min}$, respectively. The lateral etch distance increases with etching time, but is independent of ion dose.

\section{B. Nanochannel Formation with $A L D$}

ALD $\mathrm{Ta}_{2} \mathrm{O}_{5}$ was chosen as the test material as it is amorphous, insulator, chemically stable and has high refractive index. After the FIB patterned line gaps were all closed by $\mathrm{Ta}_{2} \mathrm{O}_{5}$ film, cross sections were made by FIB milling. The SEM images in Fig. 5 show the channels formed after ALD of $\mathrm{Ta}_{2} \mathrm{O}_{5}$ thin film. The ion dose used for the FIB patterning increased from left to right in each image shown in Fig. 5, which results in larger opening in the $\mathrm{SiO}_{2}$ layer. More ALD cycles were required for closing wider line gaps, resulting in thicker channel walls because the wall thickness equals to a half of the line gap.
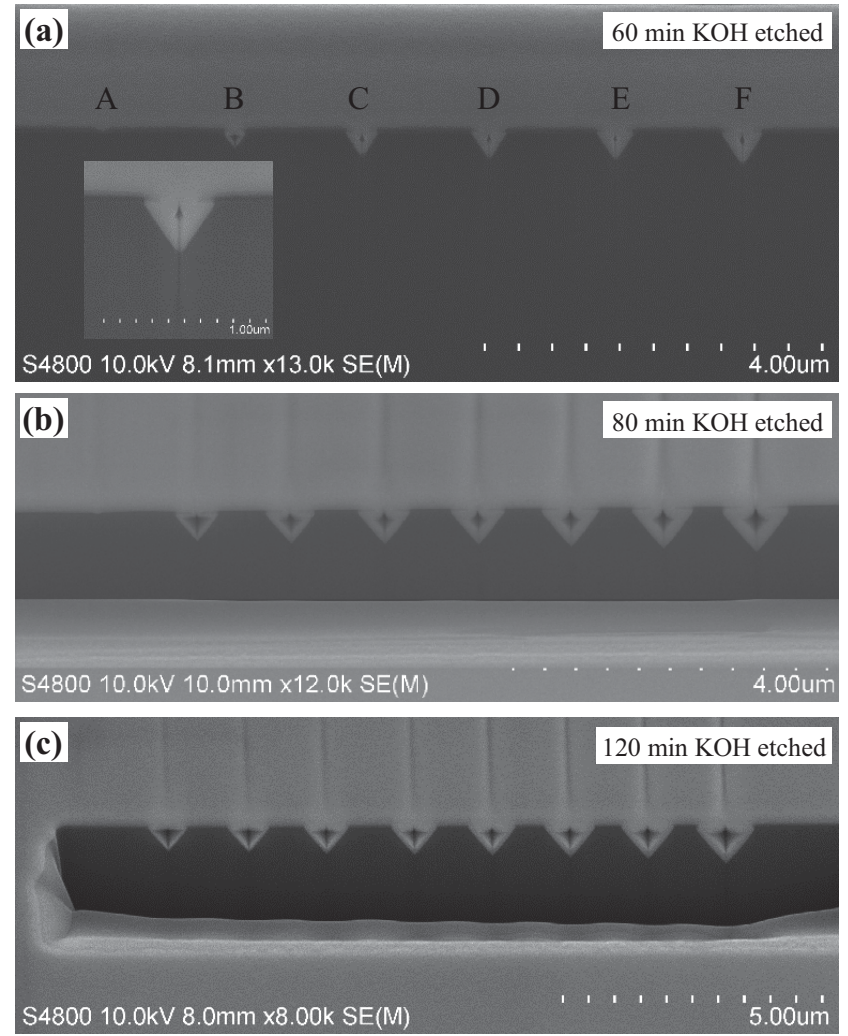

Fig. 5. Cross-section SEM images of nanochannels formed by FIB patterning, wet etching and ALD coating, corresponding to Fig. 4 (b), (c) and (d) respectively.

In Fig. 5(a), for example, the ion dose for line A made only a V-trench into $\mathrm{SiO}_{2}$ but was not sufficient to reach the $\mathrm{Si}$ underneath. This prevented the wet etching of Si and thus did not result in suspended $\mathrm{SiO}_{2}$, so no channel was formed after ALD of $\mathrm{Ta}_{2} \mathrm{O}_{5}$ for line A. The patterning ion dose for line B was sufficient for exposing $\mathrm{Si}$ which could be etched in the $\mathrm{KOH}$ solution. More and more ion milling of $\mathrm{Si}$ occurred for lines $\mathrm{C}$ to $\mathrm{F}$, which led to deeper line trenches after the $\mathrm{KOH}$ etching. Therefore, the ion dose controls both the size of line trenches before ALD and wall thickness of channels after ALD. Meanwhile, the $\mathrm{KOH}$ etching time determines the trench size and the resulting channel size. However the channel size for the same etching time does not vary significantly with the ion dose. By using ALD to form nanochannels, a wide variety of channel wall materials become available. One can also have different materials on the inside and outside the channel, if a bilayer or multilayer is deposited.

\section{CONCLUSIONS}

This paper demonstrated a resistless fabrication method for embedded $\mathrm{Ta}_{2} \mathrm{O}_{5}$ channels by FIB direct writing, wet etching and $\mathrm{ALD}$ on $\mathrm{SiO}_{2} / \mathrm{Si}$ substrates. The channel size is determined by $\mathrm{KOH}$ etching time and the wall thickness by the ion dose applied to make line opening into the $\mathrm{SiO}_{2}$ layer. The wall materials can be selected depending on the application such as metals, oxides and nitrides as they are widely available in ALD processes, making this a highly versatile approach. 


\section{ACKNOWLEDGMENT}

We wish to acknowledge financial support from China Scholarship Council (File No. 2011704017). We also gratefully acknowledge Finnish center of excellence in atomic layer deposition.

\section{REFERENCES}

[1] R. Nagarajan, B. R. Murthy, and A. Linn, "Ultra-high aspect ratio buried silicon nano-channels for biological applications," IEEE Sensors, Vols 1-3, pp. 1276-1280, 2006.

[2] I. J. Park, S. G. Jeon, and C. Shin, "A new slit-type vacuum-channel transistor," IEEE Trans. Electron Devices, vol. 61, pp. 4186-4191, Dec 2014.

[3] H. Daiguji, P. D. Yang, and A. Majumdar, "Ion transport in nanofluidic channels," Nano Lett., vol. 4, pp. 137-142, Jan 2004.

[4] S. Howorka, S. Cheley, and H. Bayley, "Sequence-specific detection of individual DNA strands using engineered nanopores," Nat. Biotechnol., vol. 19, pp. 636-639, Jul 2001.

[5] M. Leskela and M. Ritala, "Atomic layer deposition chemistry: Recent developments and future challenges," Angew. Chem. Int. Ed. Engl., vol. 42, pp. 5548-5554, Nov 2003.

[6] V. Miikkulainen, M. Leskelä, M. Ritala, and R. L. Puurunen, "Crystallinity of inorganic films grown by atomic layer deposition: Overview and general trends," J. Appl. Phys., vol. 113, p. 021301, Jan 082013.

[7] I. Perez, E. Robertson, P. Banerjee, L. Henn-Lecordier, S. J. Son, S. B. Lee, et al., "TEM-based metrology for $\mathrm{HfO}_{2}$ layers and nanotubes formed in anodic aluminum oxide nanopore structures," Small, vol. 4, pp. 1223-1232, Aug 2008.

[8] M. Leskela, M. Kemell, K. Kukli, V. Pore, E. Santala, M. Ritala, et al., "Exploitation of atomic layer deposition for nanostructured materials," Mater. Sci. Eng., C, vol. 27, pp. 1504-1508, Sep 2007.

[9] M. Kemell, E. Harkonen, V. Pore, M. Ritala, and M. Leskela, " $\mathrm{Ta}_{2} \mathrm{O}_{5^{-}}$ and $\mathrm{TiO}_{2}$-based nanostructures made by atomic layer deposition," Nanotechnology, vol. 21, p. 035301, Jan 2010.

[10] M. Kemell, V. Pore, M. Ritala, M. Leskela, and M. Linden, "Atomic layer deposition in nanometer-level replication of cellulosic substances and preparation of photocatalytic $\mathrm{TiO}_{2} /$ cellulose composites," JACS, vol. 127, pp. 14178-14179, Oct 2005.

[11] E. Santala, M. Kemell, M. Leskela, and M. Ritala, "The preparation of reusable magnetic and photocatalytic composite nanofibers by electrospinning and atomic layer deposition," Nanotechnology, vol. 20, p. 035602, Jan 2009.

[12] E. Santala, J. Hamalainen, J. Lu, M. Leskela, and M. Ritala, "Metallic Ir, $\mathrm{IrO}_{2}$ and $\mathrm{Pt}$ nanotubes and fibers by electrospinning and atomic layer deposition," Nanosci. Nanotech. Lett., vol. 1, pp. 218-223, Dec 2009.

[13] C. Marichy, N. Donato, M. Latino, M. G. Willinger, J. P. Tessonnier, G. Neri, et al., "Gas sensing properties and p-type response of ALD $\mathrm{TiO}_{2}$ coated carbon nanotubes," Nanotechnology, vol. 26, p. 024004, Jan 2015 .
[14] S. H. Jin, G. H. Jun, S. H. Hong, and S. Jeon, "Conformal coating of titanium suboxide on carbon nanotube networks by atomic layer deposition for inverted organic photovoltaic cells," Carbon, vol. 50, pp. 4483-4488, May 2012.

[15] T. Serikawa and T. Yachi, "Lift-off patterning of sputtered $\mathrm{SiO}_{2}$-films," J. Electrochem. Soc., vol. 128, pp. 918-919, 1981.

[16] T. Yachi and T. Serikawa, "Lift-off patterning of sputtered $\mathrm{SiO}_{2}$-films (lopas) and its application to recessed field isolation," J. Electrochem. Soc., vol. 132, pp. 2775-2778, 1985.

[17] C. Shafai, M. J. Brett, and T. M. Hrudey, "Etch-induced stress failures of $\mathrm{SiO}_{2}$ cantilever beams," Sens. Actuators, A, vol. 70, pp. 283-290, Oct 1998.

[18] D. R. Allee and A. N. Broers, "Direct nanometer scale patterning of $\mathrm{SiO}_{2}$ with electron-beam irradiation through a sacrificial layer," Appl. Phys. Lett., vol. 57, pp. 2271-2273, Nov 1990.

[19] P. E. Allen, D. P. Griffis, Z. J. Radzimski, and P. E. Russell, "Electronbeam patterning of $\mathrm{SiO}_{2}$," J. Vac. Sci. Technol., A, vol. 10, pp. 965-969, Jul-Aug 1992.

[20] J. W. Lussi, C. Tang, P. A. Kuenzi, U. Staufer, G. Csucs, J. Voros, et al., "Selective molecular assembly patterning at the nanoscale: A novel platform for producing protein patterns by electron-beam lithography on $\mathrm{SiO}_{2}$ /indium tin oxide-coated glass substrates," Nanotechnology, vol. 16, pp. 1781-1786, Jul 2005.

[21] J. Q. Huang, Q. A. Huang, M. Qin, W. J. Dong, and X. W. Chen, "Experimental study on the dielectrostriction of $\mathrm{SiO}_{2}$ with a microfabricated cantilever," IEEE Sensors, Vols 1-3, pp. 1030-1033, 2009.

[22] K. Shimizu and S. Oda, "Fabrication of mos nanostructure by employing electron-beam lithography and anisotropic wet etching of silicon," Jpn. J. Appl. Phys., Part 2, vol. 30, pp. L415-L417, Mar 1991.

[23] B. Klehn and U. Kunze, "SiO ${ }_{2}$ and $\mathrm{Si}$ nanoscale patterning with an atomic force microscope," Superlattices Microstruct., vol. 23, pp. 441444, 1998.

[24] S. W. Kim, T. Kotani, M. Ueda, S. Fujita, and S. Fujita, "Selective formation of Zno nanodots on nanopatterned substrates by metalorganic chemical vapor deposition," Appl. Phys. Lett., vol. 83, pp. 3593-3595, Oct 2003.

[25] M. Tanaka, K. Furuya, and T. Saito, "In-situ observation of focused ion beam micropatterns on semiconductors and insulators," Jpn. J. Appl. Phys., Part 1, vol. 37, pp. 7010-7014, Sept 1998.

[26] C.-S. Kim, S.-H. Ahn, and D.-Y. Jang, "Review: Developments in micro/nanoscale fabrication by focused ion beams," Vacuum, vol. 86, pp. 1014-1035, Nov 2011.

[27] Z. Han, M. Vehkamäki, M. Leskelä, and M. Ritala, "Selective etching of focused ion beam implanted regions from silicon as a nanofabrication method," Nanotechnology, vol. 26, p. 265304, Jun 2015.

[28] B. E. Deal and A. S. Grove, "General relationship for thermal oxidation of silicon," J. Appl. Phys., vol. 36, pp. 3770-3778, Dec 1965.

[29] A. Pasquarello, M. S. Hybertsen, and R. Car, "Interface structure between silicon and its oxide by first-principles molecular dynamics," Nature, vol. 396, pp. 58-60, Nov 1998.

[30] I. Zubel and I. Barycka, "Silicon anisotropic etching in alkaline solutions I. The geometric description of figures developed under etching $\mathrm{Si}(100)$ in various solutions," Sens. Actuators, A, vol. 70, pp. 250-259, Oct 1998. 